AperTO - Archivio Istituzionale Open Access dell'Università di Torino

\title{
Gender matter and the challenge for improving community health and well-being
}

\section{This is a pre print version of the following article:}

Original Citation:

Availability:

This version is available http://hdl.handle.net/2318/1734872

since 2020-04-02T12:36:16Z

Published version:

DOI:https://doi.org/10.1080/10852352.2019.1624351

Terms of use:

Open Access

Anyone can freely access the full text of works made available as "Open Access". Works made available under a Creative Commons license can be used according to the terms and conditions of said license. Use of all other works requires consent of the right holder (author or publisher) if not exempted from copyright protection by the applicable law. 


\title{
Gender matter and the challenge for improving community health and well-being Laura Migliorini *, Nadia Rania *, Norma De Piccoli N. ** \\ * Department of Education Sciences, University of Genoa, Italy \\ ** Department of Psychology, University of Turin, Italy
}

\begin{abstract}
Present paper introduces the special issue focused on the gender perspective and health in the community in Italian context. After a brief analysis of the disparity and inequity that still persist at the European and Italian level, we present six papers realized in different Italian region that demonstrate different elements of the complex gender matter and challenges of well-being and health process in the community. Taking into account the differences between men and women from social vulnerability and risk point of view, and the unequal power relationships between the sexes could improve the efficacy of intervention and prevention actions. Through these series of papers, we aimed to contribute to the debate about how gender perspective can shape the study and the intervention in the to promote health and well-being that takes into account both individual and community health. Gender is revealed in many ways one of the key determinants of health in order to better understanding and planning intervention in health services, improving the health of women and men. Furthermore, more attention and reflection are needed to promote policy interventions for health and to consider he contribution of the woman to the health of the community.

Keywords: gender perspective, health-promotion, community
\end{abstract}

The present issue examines the gender matter to enhance the promotion of well-being and health in the community. We will deal with the importance of women community engagement to strengthen individual well-being and community health, emphasizing the need of gender approach in health care, professional service and spontaneous community initiatives. Gender role development is one of the 
most important areas of community development (Bond, Serrano-Garcia, 2017). In fact, gender refers to the roles, responsibilities, attributes, and power relations that are socially constructed by and assigned to men and women of a given society or community. These constructs vary greatly by culture, geographic region, socioeconomic status, and context, and they change over time. Perceptions of gender are deeply rooted, vary widely both within and between cultures, and change over time. But in all cultures, gender determines power and resources for females and males.

The gender gap according to Salmi (2016) is universal, and pervades culture, science, economy and all formal and informal social groups; furthermore, has relapses on health and access to education. For this reasons it is an important issue that is addressed by different disciplines in the field not only of the social sciences but also in the life sciences. Despite the analyzes and reports of inequalities in male-female relationships, the gap in access to decision-making roles in the company and in the society has increased and power remains firmly in the hands of the male gender. This is why the fight against inequalities is one of the priority objectives of the Agenda 2030 of United Nations for Sustainable Development, which outlines a close link between women's empowerment and development and recommends an approach based on gender, generation, territory and ethnicity, across all objectives set to guide policies and strategies. Recently, the Global Gender Gap Report 2017 of the World Economic Forum reports the annual ranking by which by which the gender gap is measured each year based on four dimensions: economic participation and opportunities, education, health and survival, political empowerment. We select some information describing USA, Europe and Italy situation just to give some general information about differences. The Report shows that "The United States (49 out of 144) moves down four spots compared to last year. It records some improvement on the Economic Opportunity and Participation sub index - in particular due to a smaller gender gap on the wage equality for similar work indicator-but experiences a decline on the Political Empowerment sub index, which stands at its lowest level since 2007, due, in particular, to a significant decrease in gender parity in ministerial level positions. More positively, the United States has fully closed its gender gap in Educational Attainment for a number of years, highlighting the 
substantial potential of the country's next-generation female workforce. The United States has closed nearly $72 \%$ of its overall gender gap, a decrease of $2 \%$ since 2015 " (p. 22). "Western Europe remains the highest performing region in the Index in 2017. However, it is also one of the regions with the widest performance variation, seeing progress stall or even reverse across a number of countries this year. Western Europe is home to four of the top five countries in the Index-Iceland, Norway, Finland and Sweden-highlighting the continued progress of the Nordic countries in closing their overall gender gaps. At the bottom ranks of the region, four countries have a remaining gender gap of more than 30\%: Greece, Italy, Cyprus, and Malta. No country in the region has managed to fully close both its Educational Attainment and its Health and Survival gender gaps this year" (p. 24). Italy since 2006, the year of creation of the index, continues to backward, and in the last year loses 22 positions (82 out of 144) while France and Germany are in 11th and 12th place, Great Britain at 15th. Italy furthermore, "sees a drop in wage equality for similar work and women in ministerial roles, and widens its gender gap to more than $30 \%$ for the first time since 2014” (p. 25).

According to ISTAT (2017) data on gender equality in Italy, it emerges that women in our country are on average more educated than men and more difficult to abandon their studies. However, the data confirm that, although higher qualifications are a greater guarantee of access to the labor market, employment rates for women are still very low. The data show that one of the determinants of this Italian framework lies in the low sharing among the family members of the management of work and care time. For women who take part in the world of work, therefore, more discontinuous careers and lower pay can be traced back to the lower possibility of access to senior figures. Although important positive signs emerge on the front of women in decision-making and political places, constantly increasing year after year. However, the female presence in the top bodies of public institutions is very limited: it does not reach 15 percent $(14.4 \%)$. Looking at the legal form, the lowest value is found in the universities ( $7.2 \%$ of women's top) and the highest in the constitutional bodies (21.2\%). Differences in gender roles and behaviors often create inequalities; gender becomes empowered to the disadvantage of the other. In all societies, in fact women are still viewed as subordinate to men 
and have a lower social status, allowing men greater decision-making power. Recognizing the role of women in the community and giving meaning to this role is a starting point for promoting fair society. The change of the perception and the consideration of women could improve not only their condition but also the condition of society in general. Gender inequalities have a large and wide-ranging impact on society; for example, they can contribute to gender inequities in health and access to health care, opportunities for employment and promotion, levels of income, political participation and representation and education.

The literature has dealt mainly with the role of women in the field of prevention (Östlin, Eckermann, Mishra, Nkowane, Wallstam, 2006; Williamson, Knox, Guerra, \& Williams, 2014). The researchers less focus on the aspect of health intended as psychological well-being. However, since 1948 the World Health Organization defines health as the state of complete physical, mental and social wellbeing, and not only as an absence of disease. The literature holds that well-being has important health implications; therefore, the self-perception of health, characterized by positive feelings toward oneself, a feeling of self-control and an optimistic outlook on the future, not only provides a leading force for coping with the difficulties of everyday life, but also with those stressful situations that threaten existence (Vazquez, Hervas, Rahona, \& Gomez, 2009). However, the relationship between well-being and health is complex and seems to favor health in various ways as by research teams evidenced by the epidemiological studies of the seventies that have maintained that social support preserves from both mental and physical illness. In the relationship between health and well-being there is a gap between those who refer to a "classic" and traditional apportion, from a positivist perspective, tending to be medical, and those that refer to the paradigm of the promotion of health, or that recognize themselves in a critical perspective (Murray, 2004; Marks, Murray, Evans, \& Estacio, 2011) considering health in line with the definition of WHO in the bio-psycho-social aspects. What is further developed is a gender perspective, often considered only in its care role, thus risking consolidating a stereotypical aspect of the female role. 
Through the analysis of the results of research intervention and theoretical considerations, we will try to focus the role of women in community as factors inherent in the context of life from the environmental point of view (structural and demographic characteristics), social (socio-economic inequalities, relationships and social support), cultural (status gap). Overall these dimensions influence health and disease and implications for interventions to promote wellbeing of which social policies but also health policies could be considered in order to not reiterate an androcentric model of health and well-being.

In planning and collecting this issue regarding gender perspective on health and well-being we asked ourselves how gender perspective can shape the study and the intervention in the community. The present issue therefore focuses on some interesting contributions that seek to capture and examine the role of women as promoters of health and relational well-being in order to bring out the aspects that too often remain not very visible but which are important and promoters of development of a country and its generations. The issue also aims to give a contribution on the experiences of creating and implementation of policies for prevention and health promotion by gender point of view, because health equity policies cannot ignore the need to develop scientific knowledge that considers gender specificities.

In the first contribution, titled "Gender perspective in the Community as promotion of wellbeing and Health", Migliorini and De Piccoli examine the role of gender perspective in order to promote healthy context in the community. The literature shows that pay attention to gender equity affect numerous indicators of community wellbeing. After analyzing gender as social role and as context, the authors describe how sex and gender in health sector is considered, because in this scientific context, resistances to a change of perspective seem to persist The attention to gender equity make community more competent in order to create human and social capital that enables community well-being.

Bosco, Giaccherini, and Meringolo examine “A gender perspective about young people’s seeking help", focusing on young people's perceptions about psychological help seeking for mental 
health issues. The paper includes two studies both qualitative and quantitative methods. Results show that in case of psychological distress, young people, and particularly males, tend to seek help from those they know and trust, while females seem to have more confidence in adult and mental health professionals. Moreover, data show that self-reliance is considered as the preferred coping strategy adopted by young males to deal with their psychological problems.

A group of authors focus instead on the gender-medicine approach: the contribution of Gattino, De Piccoli, and Rollero "Awareness of Gender Medicine among family doctors. A field investigation" discusses on gender differences in health and illness. A large body of evidence has shown that gender is one of the key determinants of health to improve gender equity in health services, to enhance the health of women and men. Despite this, gender medicine is ignored. This makes difficult to address the needs of either women or men to receive the appropriate attention in terms of medical diagnosis. Currently there is an increase and a progress on this issue, highlighting the need to strengthen the socalled Gender Medicine. Based on these considerations, the authors have conducted a study aimed at describing how spread the Gender Medicine awareness is among general practitioners. The results show the relevance of this topic and the need to implement training programs to enhance gender awareness both in experienced physicians and those in training. The results highlight the need of policies that take into account bio-psycho-social aspects that explain differences in health and illness between women and men.

Neighborhood contexts influence the availability of positive and negative role models, the ease with which relationships are formed, and a variety of emotions and attitudes. Rania, Migliorini, Zunino, and Lena, in their paper titled "Psychological well-being and health community: women as marker of relational well-being by social street strategies", present a Social Street experience born of the desire to build a new neighborhood strategy in order to linking and enhancing community ties and well-being. Social Street network that starts from Facebook to relaunch people's involvement through micro-networks linked to the streets of the city and where, from a first virtual passage and knowledge, it passes directly to the realization of events and concrete proposals of mutual help. The aim of the 
paper is exploring social street phenomenon from the relationship between individuals and their community point of view. The authors analyze the effectiveness of Social Street through the study of social networks and take into account as gender could became a relational context variable inside the community. In fact, the role of women in social street strategies is relevant in structuring relational contexts improving community network and relationship.

The paper of Camussi, Zulato, Sassi, and Annovazzi “Haking Women's Health: a New methodology" describes a new approach to Public Engagement already tested by the authors in the healthcare context. The authors focusing on a gender perspective propose to apply the methodology to gender-related, social innovation projects, by when promoting enhancements in community health. The Methodology assemblies the psychosocial perspective of Participatory Research "Human Centered" approach and promote a process that is innovative, interdisciplinary, technological, and sustainable. The final aim is to find viable solutions to real problems through the engagement of a community of both experts and citizens in a three-step process called Awareness-ActivationParticipation.

Di Napoli and Arcidiacono in their paper "Women's associations and the well-being of their members: from mutual support to full citizenship" investigate the power in women's associations and well-being of their members. The main aim was to investigate the dimensions of power carried out and suffered within a gender perspective, in order to detect the forms and modalities according to which these associations successfully acted in their local context. Thirty-nine contacts from feminist associations were interviewed. The textual material obtained was analyzed according to the Grounded Theory Methodology and was then reinterpreted in a gender perspective in accordance with the categorizations defined by the ecological model of Prilleltensky (2008). The results showed that associations produced well-being and empowerment at the individual and organizational levels, but that they were unable to increase and create well-being and social justice at the Macro level. The ecological model proved to be particularly valuable in order to reflect upon the effectiveness of women's activities and feminist initiatives. The research gave then some indication concerning 
women actions in active groups and the related individual well-being, but at the same time, highlighted their difficulties in having a transformative role at community level.

Given the importance of gender issue across the communities, there is the need to propose for both innovative and carefully projects. Promoting gender perspective, it also means promoting gender equity that could prevent violence against women in an extensive sense influencing health and wellbeing. This issue provides an integrative view of the relationship between gender perspective and community. The different roles and behaviours of females and males are shaped and reinforced by gender norms within society. It is necessary transforming socio-cultural norms, with an emphasis on empowering women and girls considering their role in the community. Further research is needed in order to acquire evidence that shows as context interventions can promote gender equality. Community interventions and informal initiatives can address gender norms and attitude and promoting health interventions to enhance supportive context, good living conditions, community involvement and participation, access to social and health (Östlin, Eckermann, Mishra, Nkowane, \& Wallstam, 2006).

Furthermore, recognizing the vital role of women and seek to strengthen community ties could promote a sense of community. The innovative aspect of the interventions is to consider the level of community as a salient for the effectiveness of the intervention itself (Green \& Kreuter, 2005; Uthman, Lawoko, \& Moradi, 2010). Furthermore the empowerment and contextual approach could enhance a more holistic conceptualization of health and promoting health and well-being more linking in community development and systems change (Lardon, Soule, Kernak, \& Lupie, 2011). Finally, to promote the active women participation could provide a valued insight in the policies that have to deal with the gender implications. Policy advocacy should therefore be one of the major roles of community level health interventions; the attention of special needs of women by society and policy should promote effective and gender sensitive interventions in order to enchanting health and wellbeing in the all community. 
Running head: GENDER CHALLENGE FOR IMPROVING COMMUNITY HEALTH

\section{References}

Bond, M.A., Serrano-Garcia, I., Keys, C. (2017). "Handbook of Community Psychology Volume 1: Theoretical Foundations, Core Concepts, and Emerging Challenges. ," American Psychological Association Press, 1.

Green, L.W., \& Kreuter, M.W. (2005). Health program planning: An educational and ecological approach. 4th. New York: McGraw-Hill.

Istat (2017) Indagine conoscitiva sulle politiche in materia di parità tra donne e uomini, Roma, 25 ottobre 2017.

Lardon, C., Soule, S., Kernak, D., \& Lupie, H. (2011). Using strategic planning and organizational development principles for health promotion in an Alaska Native community Journal of Prevention and Intervention in the Community, 39(1): 65-76. Doi:10.1080/10852352.2011.530167

Marks, D., Murray, M., Evans, C., \& Estacio, E.V. (2011). Health-Psychology-Theory-ResearchPractice, Third edition. London: Sage.

Murray, M. (Ed.) (2004).Critical-Health-Psychology London:Palgrave/MacMillan

Östlin, P., Eckermann, E., Mishra, U. S., Nkowane, M., \&Wallstam, E. (2006) Gender and health promotion: a multisectoral policy approach. Health Promotion International. 21:25-35.

Prilleltensky, I. (2008) The role of power in wellness, oppression, and liberation: the promise of psychopolitical validity, Journal of Community Psychology 36(2):116 - 136 Doi:10.1002/jcop.20225

Salmi, E. (2016). The gender gap is universal, Italian Journal of Gender-Specific Medicine, 2(4): e133-e134.

United Nations Transforming our world: the 2030 Agenda for Sustainable Development, 21, October $2015 \mathrm{~A} / \mathrm{RES} / 70 / 1$ 
Uthman, O.A., Lawoko, S., \& Moradi, T. (2010). The role of individual, community and societal gender inequality in forming women's attitudes toward intimate-partner violence against women: a multilevel analysis. World Health Population,12(2):5-17.

Vazquez, C., Hervas, G., Rahona, J.J., \& Gomez, D. (2009). Psychological well-being and health. Contributions of positive psychology. Anuario de Psicologia Clinica de la Salud, Annuary of Clinical and Health Psychology, 5, 15-27.

WHO (1948). Preamble to the Constitution of the World Health Organization as adopted by the International Health Conference, New York, 19-22 June, 1946; signed on 22 July 1946 by the representatives of 61 States (Official Records of the World Health Organization, no. 2, p. 100) and entered into force on 7 April 1948

Williamson, A.A., Knox, L., Guerra, N.G., \& Williams, K.R. (2014). A pilot randomized trial of community-based parent training for immigrant Latina mothers. American Journal of Community Psychology, 53(1-2), 47-59. http://dx.doi.org/10.1007/s10464-013-9612-4

World Economic Forum (2017). The Global Gender Gap Report, Geneva, Switzerland. 